\title{
Focal degeneration of astrocytes in amyotrophic lateral sclerosis
}

\author{
D Rossi $^{\star, 1}$, L Brambilla ${ }^{1,4}$, CF Valori ${ }^{1,4,5}$, C Roncoroni ${ }^{1}$, A Crugnola ${ }^{1}$, T Yokota $^{2}$, DE Bredesen ${ }^{2}$ and A Volterra ${ }^{1,3}$
}

Astrocytes emerge as key players in motor neuron degeneration in Amyotrophic Lateral Sclerosis (ALS). Whether astrocytes cause direct damage by releasing toxic factors or contribute indirectly through the loss of physiological functions is unclear. Here we identify in the hSOD $1{ }^{\mathrm{G} 93 \mathrm{~A}}$ transgenic mouse model of ALS a degenerative process of the astrocytes, restricted to those directly surrounding spinal motor neurons. This phenomenon manifests with an early onset and becomes significant concomitant with the loss of motor cells and the appearance of clinical symptoms. Contrary to wild-type astrocytes, mutant hSOD1-expressing astrocytes are highly vulnerable to glutamate and undergo cell death mediated by the metabotropic type-5 receptor (mGluR5). Blocking mGluR5 in vivo slows down astrocytic degeneration, delays the onset of the disease and slightly extends survival in hSOD1 ${ }^{\mathrm{G} 93 \mathrm{~A}}$ transgenic mice. We propose that excitotoxicity in ALS affects both motor neurons and astrocytes, favouring their local interactive degeneration. This new mechanistic hypothesis has implications for therapeutic interventions.

Cell Death and Differentiation (2008) 15, 1691-1700; doi:10.1038/cdd.2008.99; published online 11 July 2008

Amyotrophic Lateral Sclerosis (ALS) is a neurodegenerative disorder characterized by the progressive degeneration of corticospinal and spinal motor neurons. In about $1-2 \%$ of patients, the disease is linked to mutations in the gene coding for $\mathrm{Cu}-\mathrm{Zn}$ superoxide dismutase (SOD1). ${ }^{1}$ Transgenic animals $^{2-4}$ that overexpress mutant human SOD1s (hSOD1s) develop progressive ALS-like disease. The cascade of events ultimately responsible for motor neuron degeneration, however, remains elusive.

Important insights come from the observations that death of motor cells involves both cell-autonomous and non-cellautonomous disease mechanisms, implying that mutant hSOD1 expression in neurons is sufficient to trigger the disease, ${ }^{5}$ but also the interaction of motor neurons with the neighboring glial cells contributes to the deleterious process. ${ }^{6}$ These observations have brought attention to the abnormalities affecting glial cells in ALS. In both human cases and animal models, microglia and astrocytes undergo massive activation in regions of motor neuron loss. ${ }^{7,8}$ Microglial alterations were shown to be implicated in disease progression in transgenic mice ${ }^{7,9}$ and the contribution of astrocytes to motor neuron degeneration is gaining more and more consideration. A recent study reports that mutant hSOD1 expression in astrocytes leads to motor neuron damage and accelerated disease progression by controlling microglial activation. ${ }^{8}$ Moreover, astrocytes expressing mutant hSOD1 were reported to release factors selectively toxic for motor neurons in vitro. ${ }^{10,11}$ The presence of mutant hSOD1 in these cells was also described to perturb protective functions of astrocytes towards neurons. While normal astrocytes regulate the expression of the GluR2 subunit of the AMPA receptors in motor neurons, the expression of mutant hSOD1 abolishes this property. ${ }^{12}$ Furthermore, both ALS patients and transgenic animals exhibit a defect of the astrocyte-selective glutamate transporter EAAT2/GLT1. ${ }^{3,4,13}$ EAAT2/GLT1 is crucial for controlling the physiological clearance of extracellular glutamate in the spinal cord. Thus, its loss may lead to excitotoxic glutamate levels and this could contribute to the disease progression. ${ }^{14-16}$ Another peculiar abnormality of astrocytes in hSOD1 mutant mice is the presence of Lewy body-like inclusions containing SOD1 and ubiquitin. ${ }^{3}$ Interestingly, such inclusions are the earliest indicator of disease in

\footnotetext{
${ }^{1}$ Department of Pharmacological Sciences, Center of Excellence on Neurodegenerative Diseases, University of Milan, Via Balzaretti 9, Milan 20133, Italy; ${ }^{2}$ Buck Institute for Age Research, 8001 Redwood Blvd, Novato, CA 94945, USA and ${ }^{3}$ Department of Cell Biology and Morphology, University of Lausanne, Rue du Bugnon 9, Lausanne 1005 , Switzerland

${ }^{*}$ Corresponding author: D Rossi, Department of Pharmacological Sciences, Center of Excellence on Neurodegenerative Diseases, , University of Milan, Via Balzaretti 9 , 20133 Milan, Italy. Tel: + 39025031 8327; Fax: + 39025031 8284; E-mail: daniela.rossi@ unimi.it

${ }^{4}$ These authors contributed equally to this work

${ }^{5}$ Current address: Academic Neurology Unit, University of Sheffield, Beech Hill Road, Sheffield S10 2RX, UK

Keywords: amyotrophic lateral sclerosis; apoptosis; astrocyte; excitotoxicity; metabotropic glutamate receptor

Abbreviations: ALS, amyotrophic lateral sclerosis; hSODI, human superoxide dismutase 1; AMPA, alpha-amino-3-hydxoxy-5-methyl-4-isoxazolepropionic acid; GluR2, AMPA receptor GluR2 subunit; EAAT̄2/GLT1, excitatory amino ācid transporter 2/glutamate transporter 1; GFAP, glial fibrillary acidic protein; SGPCs, spheroid GFAP-positive cells; SMI32, anti-nonphosphorylated nēurofilament $\mathrm{H}$ antibōjy from Sternberger Monoclonals Incorporated; SŌD $1{ }^{\mathrm{G} 85 \mathrm{R}}$, $\mathrm{SOD}_{1}$ harboring a single amino acid substitution of glycine to arginine at codon 85 ; SODI ${ }^{\mathrm{G} 93 \mathrm{~A}}$, SOD1 harboring a single amino acid substitution of glycine to alanine at codon 93; SOD1 ${ }^{\mathrm{WT}}$, wild-type SOD1; VGLUT1, vesicular glutamate transporter 1; EAAT1/GLAST, excitatory amino acid transporter 1/glutamate aspartate transporter; TBOA, DL-threo- $\beta$ benzyloxyaspartate; mGluR, metabotrōic glutamate receptor; MCPG, ${ }^{-}(\mathrm{S})-\alpha$-methyl-4-carboxyphenylglycine; CNQX, 6-cyano-7-nitroquinoxaline-2,3-dione; GYK1 52466, 4-(8-Methyl-9H-1,3-dioxolo[4,5-h][2,3]benzodiazepin-5-yl)-benzenamine; MPEP,' 2-methyl-6-(phenylethynyl)-pyridine; mGluR5, mētabotropic subtype 5 glutamate receptor; DHPG, (RS)-3,5-dihydroxyphenylglycine; DLTD, Asp-Leu-Thr-Asp; NG2, chondroitin sulfate proteoglycan; GDH, glutamate dehydrogenase Received 26.10.07; revised 19.5.08; accepted 20.5.08; Edited by L Green; published online 11.7.08
} 
hSOD1 ${ }^{\text {G85R }}$ mice, a transgenic line developing a late-onset, ultrarapid disease progression. Similar inclusions containing activated caspase-3 were subsequently reported in the same hSOD1 ${ }^{\text {G85R }}$ mice, as well as in hSOD1 ${ }^{\mathrm{G} 93 \mathrm{~A}}$ mice, ${ }^{17}$ a transgenic line showing earlier onset but analogously fast disease progression. However, the significance of such astrocytic inclusions remains elusive.

Here, we report in the spinal cord of hSOD $1^{\text {G93A }}$ mice that a subset of astrocytes harboring protein inclusions undergoes morphological and biochemical changes that are reminiscent of degenerating cells. Moreover, we demonstrate that the expression of mutant hSOD1s makes astrocytes vulnerable to glutamate through the activation of mGluR5 and that blockage of mGluR5 in vivo reduces astrocyte degeneration, postpones disease onset and extends lifespan.

\section{Results}

Presence of abnormal spheroid-shaped astrocytes in the lumbar spinal cord of hSOD1 ${ }^{\text {G93A }}$ mice. To study the morphological and structural changes of astrocytes during the progression of the disease, we first performed immunohistochemical analysis of lumbar spinal cord sections from hSOD ${ }^{\text {G93A }}$ and hSOD $1^{\text {WT }}$ transgenic mice, ${ }^{2}$ using the glial fibrillary acidic protein (GFAP) as an astrocytic marker. While no gross abnormalities were detected in the spinal cord of hSOD1 ${ }^{\mathrm{WT}}$ mice (Figure 1a), we found that most of the GFAPpositive cells present in sections from end-stage hSOD1 ${ }^{\text {G93A }}$ animals resembled typical reactive astrocytes with elaborated networks of long processes. In addition, we identified a subpopulation of cells displaying fully distinct features (Figure 1b). These cells exhibited a spheroid-shaped cell body with an increased diameter (mean \pm S.E.M.: $13.37 \pm$ $0.35 \mu \mathrm{m}$; range: $6.7-34 \mu \mathrm{m} ; n=88$ from six mice) compared to resting astrocytes $(9.39 \pm 0.13 \mu \mathrm{m}$; range: $4.9-15.9 \mu \mathrm{m}$; $n=145$ from 6 mice). This unusual morphology was concomitant with a reduction or even absence of GFAPpositive processes, which appeared short and abnormally thick. Immunohistochemical analysis revealed that all of the spheroid GFAP-positive cells (SGPCs) were positive for ubiquitin, which occupied most of the spheroid diameter and overlapped with the compact cap of GFAP (Figure 1c and d). Cells showing thick processes projecting off the cell body exhibited ubiquitin immunoreactivity in both the cell body and the processes (Figure 1c). About one-third of the SGPCs were immunopositive for the active form of caspase-3 (Figure $1 \mathrm{e}$ and $\mathrm{f}$ ). In general, active caspase-3 labeling had a characteristic annular shape and was circumscribed by a GFAP cap (Figure 1e), which appeared thinner and less compact than in the caspase-3-negative SGPCs (Figure 1d and f). Furthermore, active caspase-3-positive SGPCs had less GFAPpositive processes compared to caspase-3-negative SGPCs.

SGPCs appear selectively in the microenvironment of motor neurons before the symptomatic phase of ALS. To investigate whether the presence of SGPCs correlated with the area of the spinal cord affected by the disease, we focused on the distribution of these cells. Importantly, we found that they were placed exclusively in the ventral horns, where motor neurons are located, while reactive astrocytes were present both in the ventral and dorsal horn regions and in the white matter (Figure 2). To more specifically analyze the distribution of SGPCs in relation to motor neurons, we measured the interdistance between SGPCs and the motor neuron cell bodies labeled with SMI32. SGPCs resulted strictly confined to the microenvironment of motor neurons. In fact, $93 \%$ of the spheroid astrocytic cells were located within a $130 \mu \mathrm{m}$ radius of one to seven motor neurons. In $88 \%$ of the cases, the interdistance between the SGPC and the closest motor neuron was $\leqslant 40 \mu \mathrm{m}$, and in $31 \%$ it was $\leqslant 10 \mu \mathrm{m}$ (Figure 1g).

To explore this phenomenon in more detail, we then looked at the time-course of SGPC formation (Figure 3). Ubiquitinlabeled SGPCs appeared around motor neurons for the first time in 75-day-old mice (Figure 3). Their number increased by 21-fold at 100 days and by 57-fold at the end stage (Figure $3 e$ ). Analysis of the time-course of caspase-3 levels in SGPCs revealed that the active caspase-3 appeared at 100 days of age and was present in $18 \%$ of the spheroid cells. At the end stage, the percentage of active caspase-3-positive SGPCs had grown to 33\% (Figure 3e). Parallel analysis of the neighboring motor neurons revealed a decline of motor cell number, which became statistically significant at around 100 days of age and occurred in parallel to the appearance of the first signs of motor impairment (Figure 7a). ${ }^{14,18}$ Therefore, SGPC formation precedes motor neuron loss and becomes considerable in parallel to degeneration of motor cells and appearance of clinical signs.

Active caspase-3 cleaves the astrocyte GFAP cytoskeleton. The fact that active caspase-3 appears in SGPCs at late time points, when the disease has already progressed, could reflect an advanced state of degeneration of the cells. In fact, the GFAP labeling of active caspase-3positive SGPCs appeared weaker and less compact compared to caspase-3-negative SGPCs (Figure 1d and f).

Interestingly, caspase-3 was recently shown to cleave GFAP in degenerating astrocytes in Alzheimer's disease, producing a $20 \mathrm{kDa}$ GFAP carboxy-terminal fragment. ${ }^{19}$ To investigate whether caspase-3 activity might be responsible for GFAP cleavage in hSOD1 ${ }^{\mathrm{G} 93 \mathrm{~A}}$ mice, we performed western blot analysis on spinal cord homogenates from end-stage hSOD1 ${ }^{\text {G93A }}$ mice (Figure 4). Homogenates from hSOD1 ${ }^{\text {G93A }}$ mice contained a low molecular weight GFAP fragment. This fragment had the same mobility of the GFAP fragment obtained by treating homogenates from wild-type mice with recombinant active caspase-3.

Altogether, these data strongly support the conclusion that SGPCs represent a subpopulation of degenerating astrocytes in hSOD1 ${ }^{\text {G93A }}$ mice.

Expression of mutant hSOD1 confers glutamate vulnerability to astrocytes. Since excitatory afferents and dendrites of spinal motor neurons make synaptic contacts in the ventral horns, ${ }^{20}$ that is the area of SGPC formation, we decided to label glutamatergic terminals by double immunostaining with antibodies against the presynaptic marker synaptophysin and the vesicular glutamate transporter 1 (VGLUT1) (Figure 5a). Given that $92 \pm 2.3 \%$ of VGLUT1- 

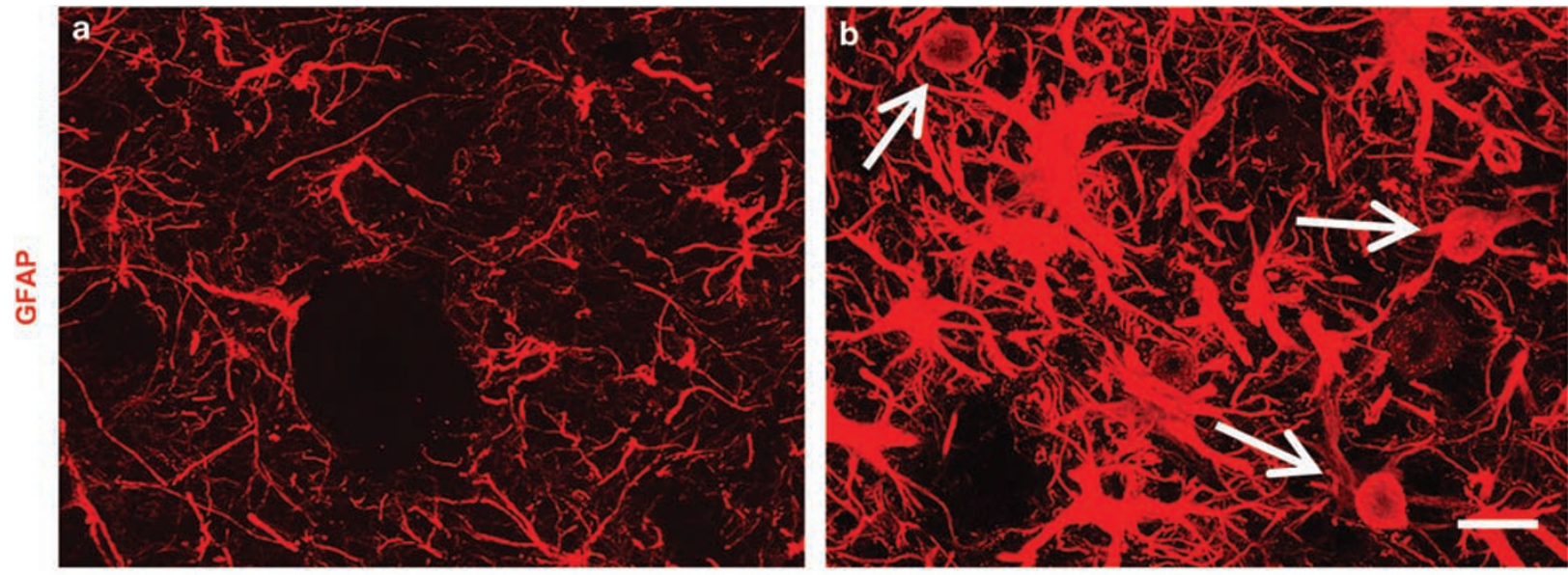

GFAPIUBIQ
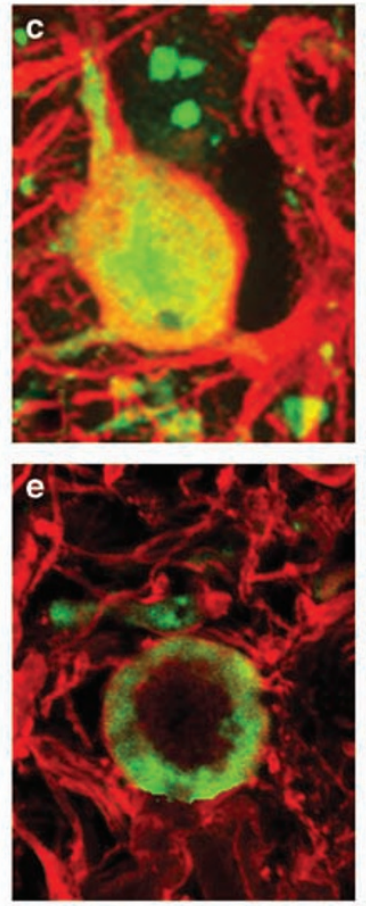

GFAPICASP3
GFAP
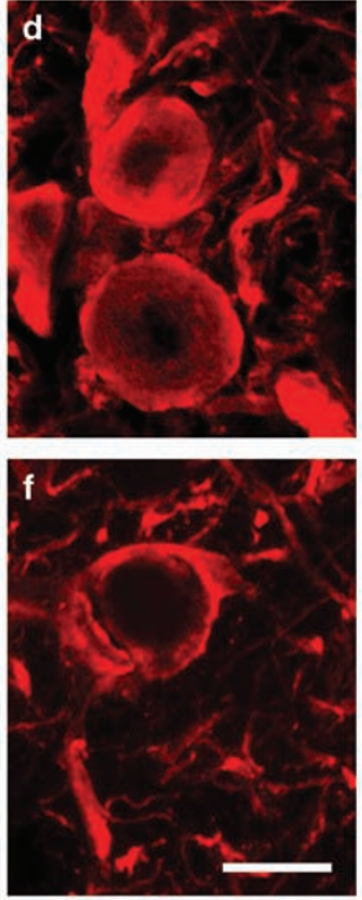

GFAP

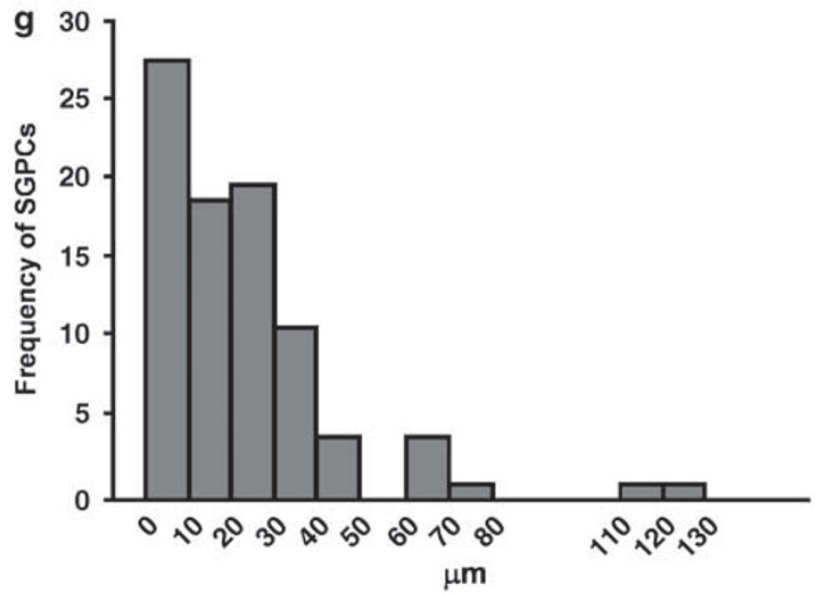

$\mu \mathrm{m}$

Figure 1 Degenerating astrocytes are located in the motor neuron microenvironment in the ventral lumbar spinal cord of hSOD1 ${ }^{\mathrm{G} 93 \mathrm{~A}}$ mice. (a and $\left.\mathbf{b}\right)$ Spheroid GFAPpositive cells (SGPCs, arrows) are located together with typical reactive astrocytes in the ventral horns of hSOD $1^{\text {G93A }}$ mice at the end stage (b), but not in the spinal cord of hSOD ${ }^{\text {WT }}$ transgenic mice (a); (c and d) all SGPCs are immunopositive for ubiquitin: some SGPCs exhibit continuous ubiquitin immunoreactivity in both the cell body and in the processes projecting off the cell body, which appear abnormally thick (c); cell bodies present a thick GFAP-positive cap (d); (e and f) SGPCs immunopositive for active caspase-3: notice the eccentric annular appearance of caspase-3 immunoreactivity in the cell body (e) and the thin GFAP cap (f). Scale bar, $20 \mu \mathrm{m}$ (a and b) and $10 \mu \mathrm{m}$ (c-f). (g) Frequency histogram shows the distribution of spheroid astrocytes around motor neurons in sections from 100-day-old mice $(n=96$ from six mice). Distance $(\mu \mathrm{m})$ from the closest motor neuron was measured from the border of the SGPC body to the border of the motor neuron cell body as defined by SMI32 immunostaining. Distances were put into bins of $10 \mu \mathrm{m}$ and their frequency distribution calculated. Only 7 out of 96 SGPCs had no adjacent motor neurons, though we cannot exclude their presence in contiguous sections

positive puncta colocalized with synaptophysin $(n=60$ fields from five mice), we concluded that, in the ventral horns of the lumbar spinal cord, VGLUT1 mostly identifies glutamatergic terminals. Using the vesicular transporter as an indicator of excitatory presynapses, we next examined the distribution of VGLUT1-positive boutons in relation to motor neurons and SGPCs. Consistent with previous reports, ${ }^{20}$ we confirmed that
VGLUT1-immunoreactive terminals surround motor neuron cell bodies and dendrites, as defined by SMI32 staining (Figure 5b). Moreover, they enclose ubiquitin-positive SGPCs around motor cells (Figure $5 c$ and $d$ ), suggesting that both cell types could sense glutamate released from those nerve terminals.

Given the altered glutamate handling reported in both sporadic ALS patients and transgenic animals,, ${ }^{3,4,13}$ we 

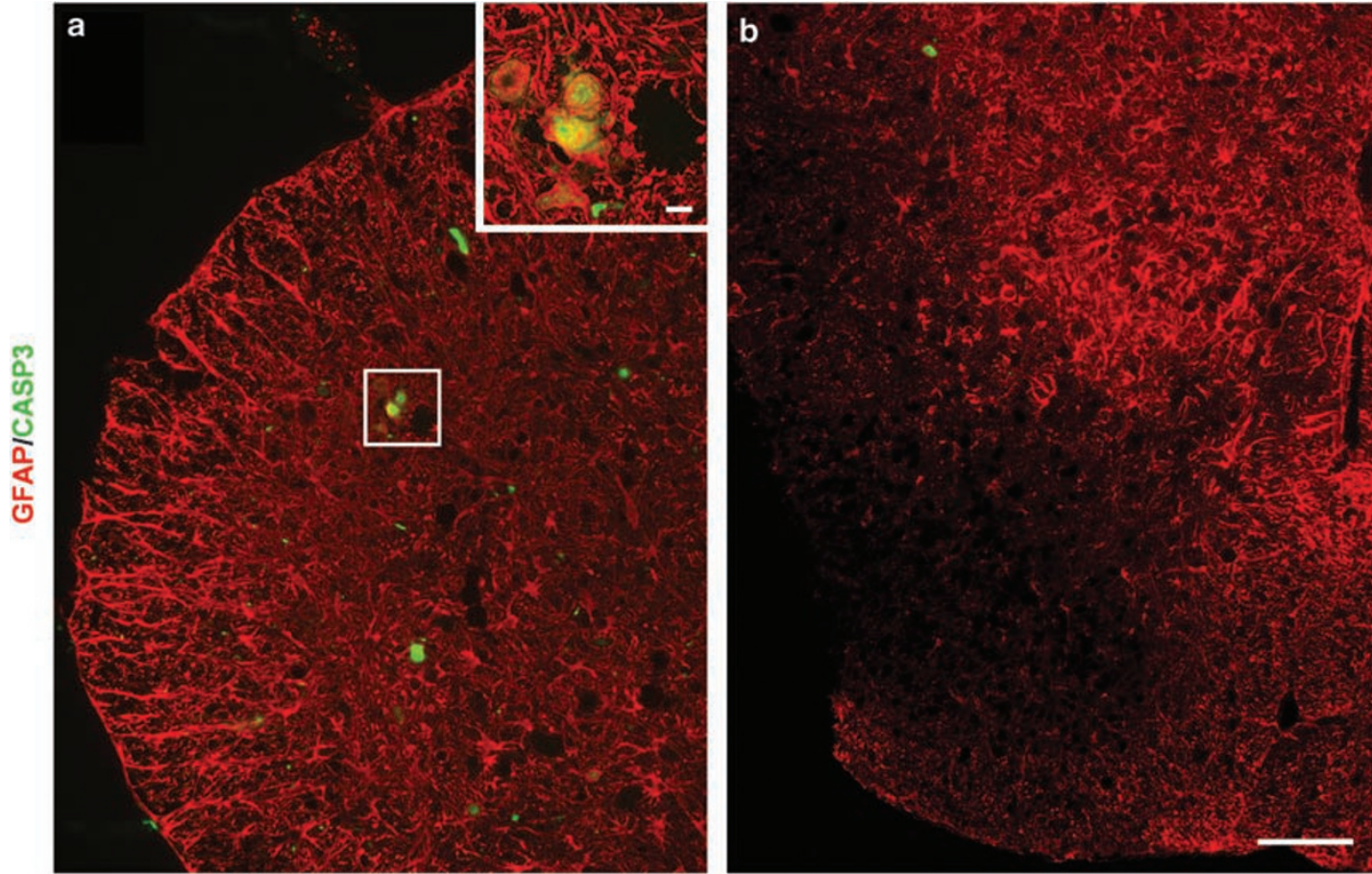

Figure 2 Degenerating astrocytes have confined distribution in the ventral region of the lumbar spinal cord. (a and $\mathbf{b})$ Double immunofluorescence staining against GFAP and active caspase-3 shows the specific localization of astrocytes containing round inclusions in the ventral horns (square box magnified in inset) (a), but not in the dorsal horns of the lumbar spinal cord (b). Scale bars, $100 \mu \mathrm{m}$ (a and $\mathbf{b})$ and $10 \mu \mathrm{m}$ (inset)
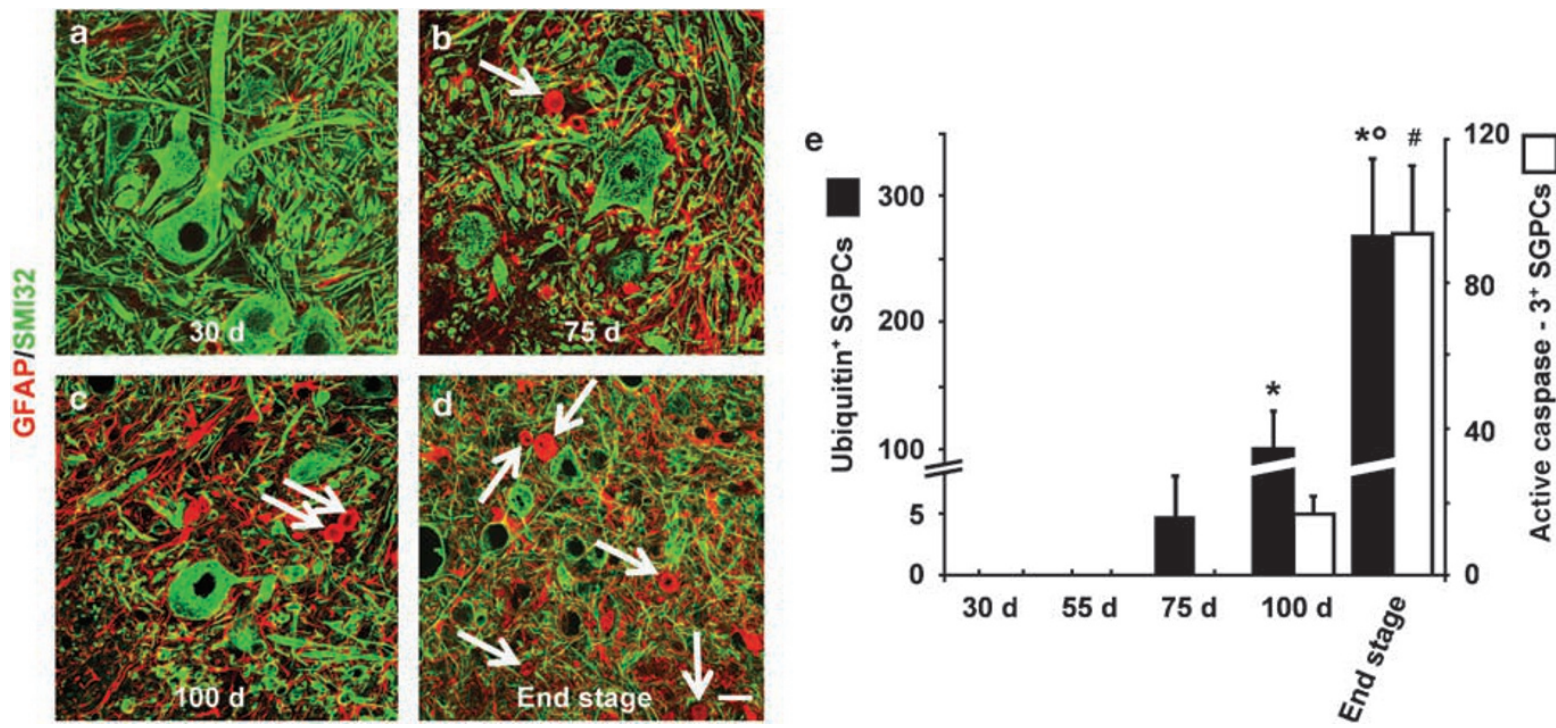

Figure 3 SGPCs appear early during disease progression in hSOD1 ${ }^{\mathrm{G} 93 \mathrm{~A}}$ mice. (a-d) An increasing number of SGPCs (arrows) directly contiguous to motor neurons appears during the disease progression. Lumbar spinal cord sections from mice at the age of 30 days (a), 75 days (b), 100 days (c) or at the end stage (d) were simultaneously labeled for nonphosphorylated neurofilaments (SMI32 antibody) and GFAP. Scale bar, $20 \mu \mathrm{m}$. (e) Time course of the appearance of abnormal spheroid astrocytes. Histogram represents the number of SGPCs double fluorescent for GFAP and ubiquitin (black bars) or GFAP and active caspase-3 (white bars, $n=4-6$ mice for each time point) at different ages during the disease progression. Values are means \pm S.E.M. (see Materials and Methods) $\left({ }^{\star} P<0.05\right.$ versus ubiquitin ${ }^{+}$SGPCs at 75 days, ${ }^{\circ} P<0.05$ versus ubiquitin ${ }^{+}$SGPCs at 100 days, ${ }^{\#} P<0.05$ versus caspase- $3^{+}$SGPCs at 100 days; ANOVA followed by the Fischer PLSD method)

investigated whether SGPCs expressed the glial glutamate transporter EAAT2/GLT1. Immunofluorescence analysis of spinal cord sections from hSOD1 ${ }^{\mathrm{G} 93 \mathrm{~A}}$ mice at the age of 100 days revealed that the SGPCs stain very weakly for this transporter (Supplementary Figure 1). Normally, expression of a highly efficient uptake system makes astrocytes resistant to glutamate concentrations toxic for neurons. ${ }^{21}$ To verify if focal astrocytic degeneration might depend on an excitotoxic 
mechanism, we prepared astrocytic cultures from the spinal cord of hSOD1 ${ }^{\mathrm{G} 93 \mathrm{~A}}$ mice and exposed them to neurotoxic glutamate concentrations $(500 \mu \mathrm{M}, 30 \mathrm{~min})$. We found that a subpopulation of astrocytes underwent delayed caspase-3 activation and nuclear condensation. This phenomenon did not occur in sister cultures of nontransgenic or hSOD1 ${ }^{\text {WT }}$ astrocytes (Figure 6a, left). In a different type of experiment, we transiently transfected wild-type rat spinal cord astrocytes with wild-type myc-tagged hSOD1 expression vectors (coding for $\mathrm{hSOD} 1^{\mathrm{WT}}$, $\mathrm{hSOD} 1^{\mathrm{G} 93 \mathrm{~A}}$ or $\mathrm{hSOD} 1^{\mathrm{G} 85 \mathrm{R}}$, respectively).

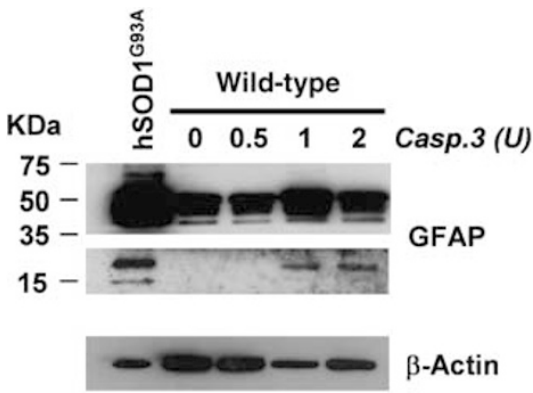

Figure 4 Active caspase-3 cleaves GFAP in the spinal cord from hSOD ${ }^{\text {G93A }}$ mice but not from wild-type mice. Representative immunoblot of spinal cord homogenates from end stage hSOD1 ${ }^{\mathrm{G} 93 \mathrm{~A}}$ mice and age-matched wild-type animals. Wild-type tissues were incubated with an increasing concentration of recombinant active caspase-3 as indicated. The blot was probed with a mouse antiGFAP monoclonal antibody that recognizes the carboxy-terminal domain of GFAP (clone G-A-5). This revealed both the full-length protein of $50 \mathrm{kDa}$ and the caspase3 -cleaved GFAP fragment of $20 \mathrm{kDa}$. No labeling of the $20 \mathrm{kDa}$ fragment was obtained in undigested tissue. $\beta$-actin was used as loading control
Exposure to glutamate induced delayed caspase-3 activation and nuclear condensation in both hSOD1 ${ }^{\mathrm{G} 93 \mathrm{~A}}$ - and hSOD1 ${ }^{\text {G85R }}$-expressing astrocytes, but not in the hSOD1 ${ }^{\mathrm{WT}}$. expressing ones (Figure 6a, right). Therefore, expression of mutant hSOD1s confers glutamate vulnerability to astrocytes.

We next estimated the ambient glutamate level ([Glu $\left.]_{0}\right)$ that is toxic for mutant hSOD1-expressing astrocytes. Since in our experimental conditions cultured astrocytes express both glial glutamate transporters, EAAT1/GLAST and EAAT2/GLT1 (Supplementary Figure 2), we artificially blocked the basal glutamate uptake with the full-spectrum transport inhibitor, DL-threo- $\beta$-benzyloxyaspartate (TBOA, $200 \mu \mathrm{M}, 30 \mathrm{~min}$ ). In hSOD1 ${ }^{\text {G93A }}$ cultures, TBOA raised [Glu] to $1.87 \pm 0.10 \mu \mathrm{M}$ ( $n=6$ in triplicate) and triggered the death of subpopulations of astrocytes (Figure 6a, left). In wild-type astrocytes, TBOA enhanced $[\mathrm{Glu}]_{\circ}$ to the same extent as in hSOD1${ }^{\mathrm{G} 93 \mathrm{~A}}$ astrocytes (to $2 \pm 0.11 \mu \mathrm{M}$ ), but had no toxic effect. Therefore, ambient glutamate concentrations as low as $2 \mu \mathrm{M}$ are selectively toxic to astrocytes expressing mutant hSOD1.

The glutamate vulnerability of mutant hSOD1-expressing astrocytes can be ascribed to mGluR5 activation. To test whether glutamate induces damage to hSOD1 ${ }^{\mathrm{G93A}}$ or ${ }^{\mathrm{G} 85 \mathrm{R}}$-expressing astrocytes through glutamate receptor-mediated signaling, we applied the amino acid in the presence of a mixture of glutamate receptor antagonists, the mGluR blocker (S)- $\alpha$-methyl-4-carboxyphenylglycine (MCPG, $500 \mu \mathrm{M})$ and the AMPA/kainate receptor antagonist, 6-cyano7-nitroquinoxaline-2,3-dione (CNQX, $10 \mu \mathrm{M}$; Figure 6b). This mixture completely prevented the glutamate toxicity.
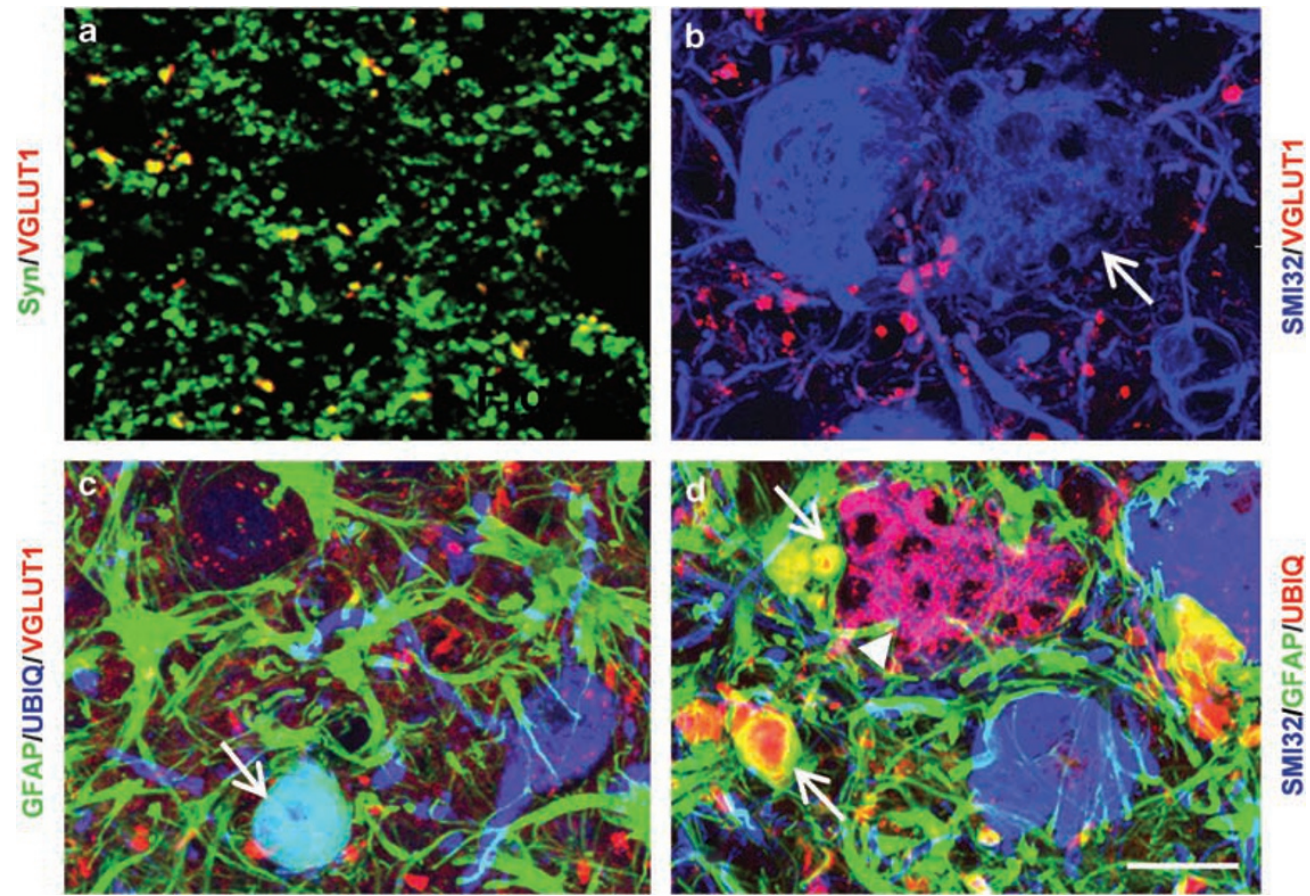

Figure 5 Degenerating astrocytes are surrounded by glutamatergic terminals immunolabeled for the vesicular glutamate transporter 1 (VGLUT1). (a) Representative image of spinal cord sections from hSOD1 ${ }^{\text {G93A }}$ mice immunostained for synaptophysin (Syn) and VGLUT1. Note the massive colocalization of synaptophysin- and VGLUT1positive puncta in the ventral horns. (b) Double immunostaining against SMI32 and VGLUT1 shows that VGLUT1-immunoreactive boutons end on motor neuron cell bodies and dendrites. Arrow indicates a suffering and vacuolated motor neuronal cell body. (c and d) Ubiquitin-positive SGPCs (arrows) are enclosed by glutamatergic presynaptic terminals (c) and they are located in the motor neuron microenvironment (d). Arrowhead indicates a ubiquitin-positive vacuolated motor neuron in (d). Scale bar, $20 \mu \mathrm{m}$ (a-d) 

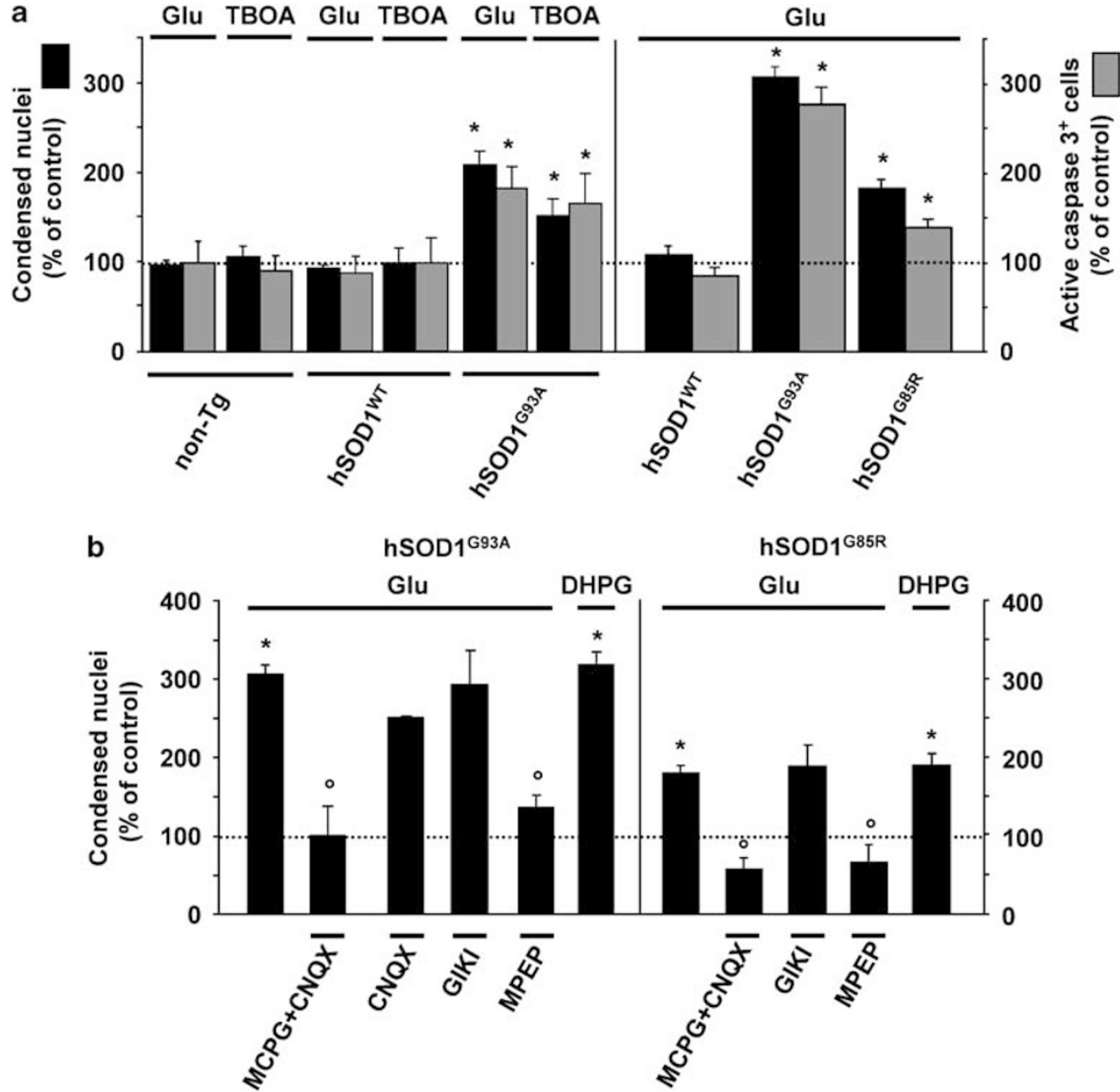

Figure 6 Expression of mutant hSOD1 confers glutamate vulnerability to spinal cord astrocytes through mGluR5-dependent signaling. (a) Left, a 30 min challenge with glutamate $(500 \mu \mathrm{M})$ or the glutamate uptake inhibitor TBOA $(200 \mu \mathrm{M})$ promotes within $24 \mathrm{~h}$ nuclear condensation (black bars) and caspase-3 activation (gray bars) in astrocyte cultures from hSOD $1^{\mathrm{G} 93 \mathrm{~A}}$ mice, but not in those from nontransgenic (non-Tg) or $\mathrm{hSOD} 1^{\mathrm{WT}}$ transgenic animals; $(n=3$ in triplicate). Data (mean \pm S.E.M.) are expressed as percentage of control, that is, the corresponding culture type challenged with saline (cells with condensed nuclei: non-Tg: $1.2 \pm 0.1 \% ; \mathrm{hSOD} 1^{\mathrm{WT}}$ : $1.3 \pm 0.1 \%$; hSOD1 ${ }^{\mathrm{G} 93 \mathrm{~A}}$ : $1.2 \pm 0.1 \%$; cells immunopositive for active caspase-3: non-Tg: $0.3 \pm 0.1 \%$; hSOD1 ${ }^{\mathrm{WT}}: 0.5 \pm 0.1 \%$; hSOD1 ${ }^{\mathrm{G} 93 \mathrm{~A}}: 0.3 \pm 0.1 \%$, respectively). Right, transfection with cDNAs encoding hSOD $1{ }^{\mathrm{G} 93 \mathrm{~A}}$ or $\mathrm{hSOD} 1^{\mathrm{G} 85 \mathrm{R}}$ mutants, but not $\mathrm{hSOD} 1^{\mathrm{WT}}$, confers glutamate vulnerability to normal astrocytes from the rat spinal cord. Experimental paradigm and data expression are as in the left panel ( $n=7$ in triplicate). Control values: cells with condensed nuclei: hSOD1 ${ }^{\mathrm{WT}}: 4.1 \pm 0.4 \%$; hSOD $1^{\mathrm{G} 93 \mathrm{~A}}: 3.5 \pm 0.4 \%$; hSOD1 ${ }^{\mathrm{G} 85 \mathrm{R}}$ : $5.2 \pm 0.5 \%$;

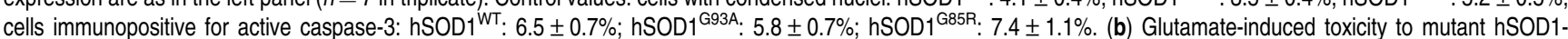
expressing astrocytes is selectively mediated by mGluR5 receptors. Rat spinal astrocytes transfected with either hSOD1 $1^{\text {G9A }}$-(left) or hSOD1 ${ }^{\mathrm{G} 85 R}$-encoding (right) expression vectors were challenged with glutamate as above, in the absence ( $n=7$ in triplicate) or in the presence of different glutamate receptor antagonists ( $n=3$ per each condition), or with the group I mGluR agonist DHPG (100 $\mu \mathrm{M} ; n=4$ in triplicate). Data are expressed as percentage of control as above $\left({ }^{\star} P<0.05\right.$ versus control (saline), ${ }^{\circ} P<0.05$ versus glutamate; ANOVA followed by Fischer PLSD method)

However, individual antagonists had different effects: CNQX, as well as GYKI $52466(50 \mu \mathrm{M})$, an AMPA receptor-selective blocker, did not prevent glutamate toxicity, whereas 2-methyl6-(phenylethynyl)-pyridine (MPEP, $200 \mathrm{nM})$, a selective mGluR5 antagonist, abolished it. Accordingly, (RS)-3,5dihydroxyphenylglycine (DHPG, $100 \mu \mathrm{M}$ ), a selective group I mGluR agonist, fully reproduced the toxic effect of glutamate (Figure 6b). Altogether, these data reveal the specific role of mGlu5 receptors in mutant hSOD1-dependent astrocyte vulnerability.

In vivo administration of the mGluR5 antagonist MPEP slows down astrocyte degeneration, delays disease onset and extends survival. On the basis of the above observations, we assessed the therapeutic efficacy of mGluR5 blockage in vivo in hSOD1 ${ }^{\mathrm{G} 93 \mathrm{~A}}$ transgenic mice. Starting at the age of 40 days, animals were treated daily with MPEP (30 mg/kg intraperitoneally) or saline. Thereafter, mice were monitored daily for the first signs of hindlimb muscle weakness and weekly for the decline in body weight. Weight gain stops at the time of disease onset, and is followed by a steady decrease, which strictly correlates with the decline in motor performance. 7,8 Thus, the peak in the body weight curve is taken as a measure of the earliest onset of disease. ${ }^{7,8}$ According to this criterion, as well as to the monitoring of hindlimb muscle weakness (not shown), we found that MPEP-treated mice showed a significant delay in the onset of the disease compared with controls (saline: 

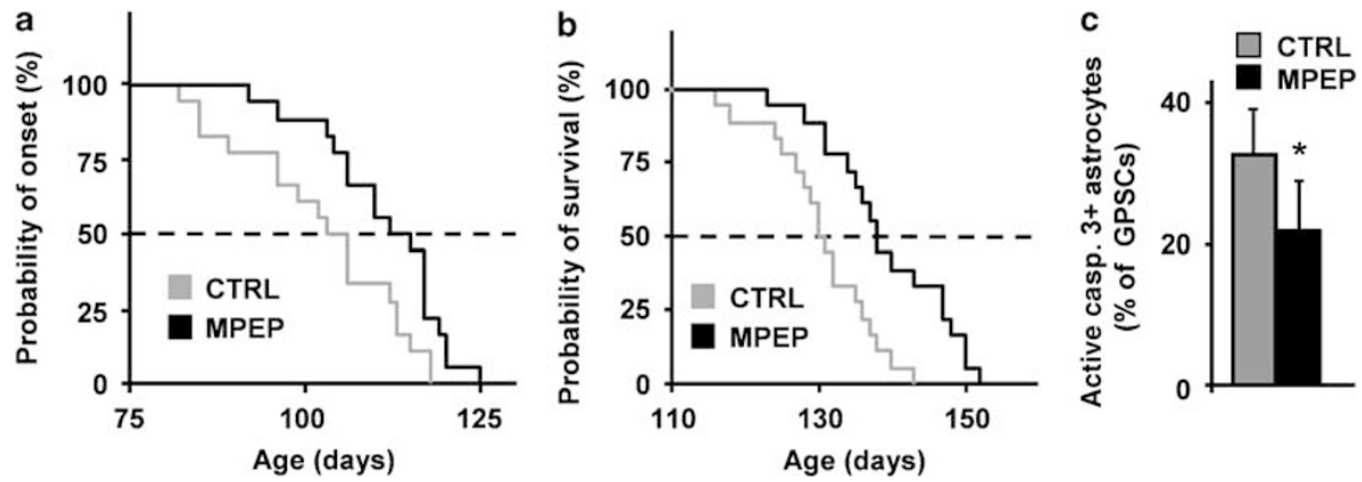

Figure 7 Treatment of $h S O D 1^{G 93 A}$ mice with the mGluR5 antagonist MPEP delays disease onset, extends survival and slows down astrocytic degeneration. ( $\mathbf{a}$ and $\mathbf{b}$ ) Kaplan-Meier curves represent the ages at which the disease onset (peak body weight) (a) and death (b) were reached for saline-treated (CTRL) and MPEP-treated (MPEP, $30 \mathrm{mg} / \mathrm{kg}$ i.p. daily) $\mathrm{hSOD} 1^{\mathrm{G} 93 \mathrm{~A}}$ mice ( $n=18$ mice for each condition). The dotted line indicates the median values in the two mouse populations. Notice that the onset of symptoms in the MPEP-treated population is significantly retarded by 9 days compared to the CTRL one $(P<0.05$; Logrank test) and life span is extended of 7 days $(P<0.01$; Logrank test). (c) Histograms indicate the percentage of spheroid GFAP-positive cells (SGPCs) that are active caspase-3-positive in sections from the end-stage saline-treated (CTRL) or MPEP-treated hSOD1 ${ }^{\mathrm{G} 93 \mathrm{~A}}$ mice ( $n=6$ mice for each condition). The number of caspase-3-positive cells is significantly lower in the MPEP-treated group ( ${ }^{*} P<0.05$; unpaired $t$-test)

$102.4 \pm 2.7$ days; MPEP: $111.4 \pm 2.1$, days; Figure $7 a)$. In addition, the mean survival in hSOD1 ${ }^{\text {G93A }}$ mice treated with MPEP (138.2 \pm 2.1 days) was slightly but significantly increased compared to hSOD1 ${ }^{\text {G93A }}$ mice treated with saline (130.6 \pm 1.7 days, Figure $7 \mathrm{~b}$ ). Therefore, these results prove the effectiveness of blocking the mGluR5 receptor in vivo.

To investigate whether the effects of MPEP on disease progression correlated to the focal degenerative process of astrocytes, we counted SGPCs in the ventral horns of control and MPEP-treated hSOD1 ${ }^{\mathrm{G} 93 \mathrm{~A}}$ mice at the end stage. While the total number of SGPCs was not statistically different in the two groups of animals (saline: $285 \pm 34$; MPEP: $258 \pm 45$ ), we found a significantly lower number of SGPCs positive for active caspase-3 in the MPEP-treated animals (saline: $93 \pm 19$; MPEP: $56 \pm 19$; Figure $7 \mathrm{c}$ ), suggestive of a less advanced stage of astrocytic degeneration.

\section{Discussion}

An increasing body of evidence indicates that degeneration of motor neurons in ALS derives from both cell-autonomous and non-cell-autonomous processes, requiring alterations in motor neurons as well as in the surrounding nonneuronal cells, particularly microglia and astrocytes. ${ }^{6}$ An important role for mutant hSOD1 expression in these glial cell types was recently demonstrated in $\mathrm{hSOD1}{ }^{\mathrm{G} 37 \mathrm{R}}$ transgenic mice by gene excision experiments. Selective reduction of mutant hSOD1 expression in microglia slowed down the late phase of the disease. ${ }^{7}$ Moreover, diminished expression of hSOD1 in astrocytes delayed the disease progression. ${ }^{8}$

The specific mechanisms by which glial cells contribute to motor neuron degeneration, however, remain elusive. Astrocytes are known to react to a variety of pathological conditions with a vigorous activation. Moreover, in ALS, they could potentially affect motor neurons in several ways, by the production of toxic species, ${ }^{10,11}$ the concurrence to the development of excitotoxicity ${ }^{12,13}$ and the modulation of the microglial inflammatory response. ${ }^{8}$
To gain further insights into the contribution of astrocytes to motor neuron degeneration, we analyzed the morphological abnormalities developed by astrocytes during ALS progression in hSOD1 ${ }^{\mathrm{G} 93 \mathrm{~A}}$ mice. By visualizing astrocytes with GFAP staining, we confirmed massive activation of astroglia throughout the spinal cord in the gray and white matter. However, we also identified a degenerative process involving a subset of astrocytes strictly confined to the microenvironment of motor neuron cell bodies, that is within the area of influence of their dendritic trees. ${ }^{22}$ The affected cells showed unusual spheroid morphology and most of them lacked the typical GFAP-positive processes. Noteworthy, all SGPCs were strongly immunopositive for ubiquitin. This, in association with the recently described proteasome failure in the lumbar spinal cord of hSOD $1^{\text {G93A }}$ mice,${ }^{23}$ may be indicative of alterations of the degradative pathways with the consequent accumulation of ubiquitinated misfolded protein inclusions within the cells. The fact that ubiquitin partially colocalizes with GFAP suggests a direct interaction between the two proteins. Thus, we deduce that GFAP is likely part of the protein aggregates, a condition which may explain the cytoskeletal disorganization identified in this subpopulation of astrocytes. At late time points, part of the SGPCs became immunopositive for active caspase-3. Importantly, a putative caspase-3 cleavage consensus DLTD ${ }^{263}$ site (DLTD ${ }^{266}$ in the human sequence) was recently identified within the GFAP amino acid sequence. ${ }^{19}$ Cleavage in this position with generation of a $20 \mathrm{kDa}$ GFAP carboxy-terminal fragment was reported in degenerating astrocytes in Alzheimer's disease. ${ }^{19}$ Thus, we investigated whether active caspase- 3 acted on the astrocytic cytoskeleton in the spinal cord of hSOD $1^{\text {G93A }}$ transgenic mice. Using an antibody that recognizes the carboxy-terminal domain of GFAP, we could confirm that recombinant caspase-3 cleaves GFAP in vitro in nontransgenic tissues. Moreover, we detected the typical $20 \mathrm{kDa}$ C-terminal fragment in the transgenic ones. Therefore, we propose that the reduced thickness of the GFAP cap and the reduced number of GFAP-positive processes in the caspase-3-positive SGPCs result from caspase-3-mediated cleavage of the astrocytic 
GFAP cytoskeleton. To correlate the degenerative process identified in astrocytes with that in motor neurons, we then evaluated the time-course of appearance of SGPCs. Interestingly, we observed the first ubiquitin-positive SGPCs at 75 days of age, that is before the loss of motor cells. From that time point on, SGPC formation progressed exponentially in parallel to motor neuron degeneration. Therefore, SGPC formation has the potential to contribute to motor neuron decline and to the onset of the symptomatic phase of ALS.

Since the ventral horn gray matter presents a great abundance of excitatory afferents, ${ }^{20}$ we decided to investigate how SGPCs interface with glutamatergic nerve terminals in the spinal cord.

In various areas of the brain, astrocytes are intimately associated with synapses, and their perisynaptic processes constitute an anatomical-functional unit, together with the presynaptic and postsynaptic elements, dubbed 'the tripartite synapse'. ${ }^{24}$ This strategic location allows astrocytes to sense and respond to neurotransmitter spilled out of the synaptic cleft during neuronal activity. ${ }^{25}$ Thus, glutamate released from excitatory presynapses during transmission can activate its receptors in the perisynaptic astrocytic processes and trigger neuron-glia signaling. ${ }^{26,27}$ In addition to glial activation by synaptic spillover, there is also evidence for direct neuron-glia communication. This can occur either through the release of transmitter from presynaptic 'ectopic sites' directly facing glia, ${ }^{28}$ or through the specific neuron-glia synaptic junctions that connect excitatory or inhibitory nerve terminals to the socalled 'NG2-glia', a peculiar type of glial cells immunopositive for the proteoglycan NG2. ${ }^{29}$ Interestingly, studies on transgenic mice identified a group of brain cells expressing both NG2 and astrocytic markers. ${ }^{30}$ We clearly do not know whether SGPCs derive from this population and receive direct neuronal input. This would be an attractive explanation for their selective vulnerability, but further investigations are necessary to clarify this possibility.

A number of observations indicates that glutamate handling is altered in both sporadic human ALS cases and mutant hSOD1expressing transgenic mice, particularly due to the loss of the astrocytic glutamate transporter EAAT2/GLT1. 3,4,13

Motor cells are potentially highly vulnerable to changes in extracellular glutamate levels as they express a large number of calcium-permeable AMPA receptors ${ }^{12,31-33}$ and have limited capacity to buffer calcium. ${ }^{34}$ Although astrocytes express functional glutamate receptors, they are normally more resistant to stimuli that are excitotoxic for neurons. However, in this study, we found that cultured astrocytes that express hSOD $1^{\text {G93A }}$ or hSOD $1^{\text {G85R }}$ become susceptible to concentrations of exogenous glutamate that are not detrimental for wild-type astrocytes. ${ }^{21}$ Moreover, they degenerate in response to a moderate increase (about $2 \mu \mathrm{M}$ ) of the endogenous ambient glutamate, induced by the uptake inhibitor TBOA. Such a glutamate concentration is reached at the astrocytic membrane during the normal excitatory neurotransmission and starts glutamate receptor-mediated intracellular signaling in astrocytes. ${ }^{27}$ Thus, it is possible that the defects of glutamate uptake in ALS - the situation mimicked by TBOA - prolong activation of astrocytic glutamate receptors and amplify the deleterious process. Noteworthy, SGPCs resulted very weakly immunopositive for EAAT2/
GLT1, suggesting a reduction of the transporter expression on these cells. A role for the metabotropic glutamate receptors in ALS was previously postulated by others. ${ }^{35,36}$ Our data add further insight into this finding by indicating that the phenomenon herein identified, that is glutamate-dependent degeneration of mutant hSOD1-expressing astrocytes, is specifically mediated by mGluR5 in vitro. This finding is particularly interesting in view of previous observations highlighting mGluR5 abnormalities in ALS. Indeed, the expression of mGluR5 in the ventral spinal cord of ALS patients was reported to be selectively upregulated in astrocytes. ${ }^{37}$ Moreover, astrocytes from hSOD1 ${ }^{\mathrm{G} 93 \mathrm{~A}}$ rats display enhanced mGluR5 expression accompanied by alterations of the coupled signal-transduction pathways. ${ }^{38}$ The potential relevance of our observations to ALS pathogenesis was confirmed by the studies in vivo. These showed that MPEP controls, at least in part, the degenerative process of astrocytes, reducing the number of caspase-3-positive SGPCs. In parallel, administration of MPEP delays motor decline and extends the survival of hSOD1 ${ }^{\text {G93A }}$ transgenic mice.

In conclusion, this study shows that a subpopulation of spinal astrocytes undergoes a degenerative process in ALS. This phenomenon is most likely relevant in the context of ALS pathogenesis because: (a) it is spatially restricted to astrocytes located in the microenvironment of motor neurons; (b) it starts when most motor neurons, although suffering, ${ }^{39}$ are still alive; (c) it is sensitive to mGluR5 blockage in vivo. These observations suggest a scenario where distressed motor neurons affect the health conditions of adjacent astrocytes. Astrocytes, weakened by the expression of mutant hSOD1, become vulnerable to stimuli, such as glutamate, present in their microenvironment, and start to degenerate. This in turn may accelerate degeneration of the neighboring motor cells in an interactive process of reciprocal damage. In this context, our data complement and extend the excitotoxic hypothesis in ALS, introducing the concept that glutamatergic alterations are noxious not only to motor neurons but also to the associated astrocytes. In particular, we identify for the first time a 'gliotoxic' role of mGluR5 and a protective action of mGluR5 antagonists. This finding opens perspectives for new therapeutic approaches where mGluR5 inhibition can be combined to treatments acting on complementary mechanisms and cell targets.

\section{Materials and Methods}

Transgenic mice. Transgenic mice expressing the human SOD1 ${ }^{\mathrm{G} 93 \mathrm{~A}}$ (B6SJLTgN(SOD1-G93A)1Gur or the human SOD1 ${ }^{\text {WT }}$ (B6SJL-Tg(SOD1)2Gur/J) ${ }^{2}$ were purchased from The Jackson Laboratories. The colonies were maintained by breeding hemizygote males to wild-type C57BI6/SJL hybrid females (Charles River Laboratories). Offspring were genotyped and used for subsequent studies.

Histological analysis. Mice were transcardially perfused with $4 \%$ buffered paraformaldehyde and spinal cords were postfixed in the same solution. The lumbar tract was removed, paraffin embedded and sectioned at $10 \mu \mathrm{m}$. On selected sections, the following immunohistochemical stainings were carried out: GFAP as astrocytic marker (mouse monoclonal antibody, 1:25, Dako; rabbit polyclonal antibody, 1:1000, Dako; mouse Alexa fluor 488 conjugated monoclonal antibody, 1:1000, Chemicon), nonphosphorylated neurofilament $H$ as neuronal marker (SMI32, mouse monoclonal antibody, 1:500, Sternberger Monoclonals Incorporated), synaptophysin (clone SY38, mouse monoclonal antibody, 1:100, Dako), VGLUT1 (rabbit polyclonal antibody, 1:3000, Synaptic Systems; rabbit polyclonal antibody fluorescence-labeled with Oyster 550, 1:1500, Synaptic 
Systems), EAAT1/GLAST and EAAT2/GLT1 (rabbit polyclonal antibodies, 0.6 and $0.4 \mu \mathrm{g} / \mathrm{ml}$, respectively), active caspase-3 (rabbit polyclonal antibody, 1:50, Cell Signalling), ubiquitin (rabbit polyclonal antibody, 1:300, Dako). To detect active caspase-3, a Tyramide Amplification System kit was used (NEN). For histopathological analysis, serial sections were immunostained for GFAP/ubiquitin or GFAP/active caspase-3 and positive astrocytes were counted for a total of 8-10 disectors using an unbiased stereologic physical disector technique.

Z-axis image stacks ( $z$-step size: $0.4 \mu \mathrm{m}$ ) were collected to generate threedimensional data sets of spinal cord sections on a Bio-Rad Radiance 2100 confocal microscope with a $60 \times$ Planapo NA1,4 oil-immersion objective in condition of optimal iris diameter as defined by LaserSharp 2000 software. To determine the spatial relationship between spheroid astrocytes and the neighboring motor neurons, image stacks were sectioned along the Z-axis using ImageJ software (National Institutes of Health) and the interdistance between the periphery of GFAP staining and the boundary of motor neuron cell body, as defined by SMI32 staining, was measured within $200 \mu \mathrm{m}$ in spinal cord sections from 100-day-old mice. Distances were put into bins of $10 \mu \mathrm{m}$ and their frequency of distribution were calculated.

Quantitative analysis of punctuate staining of VGLUT1 and synaptophysin was performed on images of the ventral horns of double stained sections from the mouse lumbar spinal cord. Five random $20 \times 20 \mu \mathrm{m}$ fields per each image were processed using the colocalization plugin of ImageJ software.

Caspase-3-dependent cleavage reaction. Spinal cord homogenates (10\%) from end stage hSOD1 ${ }^{\text {G93A }}$ mice or age-matched wild-type littermates were prepared in PBS containing 1\% CHAPS and protease inhibitors (Complete Mini, Roche). Homogenates were centrifuged at $400 \times g$ for $10 \mathrm{~min}$, supernatants were removed and stored at $-80^{\circ} \mathrm{C}$.

For caspase-cleavage experiments, $20 \mu \mathrm{g}$ of total protein were incubated for $4 \mathrm{~h}$ at $37^{\circ} \mathrm{C}$ in cleavage buffer $(50 \mathrm{mM}$ Hepes pH $7.2,50 \mathrm{mM} \mathrm{NaCl}, 10 \mathrm{mM}$ EDTA, $0.1 \%$ CHAPS, $5 \%$ glycerol, $10 \mathrm{mM} \mathrm{DTT}$ ) in the absence or in the presence of increasing concentrations of recombinant active caspase-3 (Calbiochem). Reactions were terminated by adding SDS-containing sample buffer $(50 \mathrm{mM}$ Tris $\mathrm{HCl} \mathrm{pH} 6.8,2 \%$ (w/v) SDS, 10\% (v/v) glycerol, $100 \mathrm{mM} \mathrm{DTT,} \mathrm{4 \%} \beta$-mercaptoethanol, $0.1 \%(\mathrm{w} / \mathrm{v})$ bromophenol blue) and boiling for $10 \mathrm{~min}$

Western blot analysis. Caspase-cleaved tissues or cell lysates were electrophoresed through 10\% SDS-polyacrylamide gels and transferred to nitrocellulose membranes. GFAP was detected with a mouse monoclonal antibody (clone G-A-5), which recognizes the carboxy-teminal domain of GFAP $11: 500$ Chemicon). EAAT1/GLAST and EAAT2/GLT1 were detected using rabbit polyclonal antibodies $(0.2$ and $0.1 \mu \mathrm{g} / \mathrm{ml}$, respectively). $\beta$-actin was detected with a mouse monoclonal antibody (clone AC-15; 1:3000, Sigma).

Astrocyte cultures and transfection. Primary astrocyte cultures (>99\% GFAP-positive) were prepared from the spinal cord of newborn mice (hSOD $1^{\text {G93A }}$, hSOD1 ${ }^{\text {WT }}$ or nontransgenic littermates) or rats (wild-type) as described previously, ${ }^{40}$ plated at a density of $8 \times 10^{4}$ cells/well in 24-well plates containing glass coverslips and maintained in minimal essential medium (MEM) supplemented with $10 \%$ fetal calf serum. Confluent mouse cultures were directly used for experiments with pharmacological challenges. Rat spinal cord astrocytes were transfected $24 \mathrm{~h}$ after plating with the marker plasmid pEGFP-C3 $(0.5 \mu \mathrm{g}$, Clontech Laboratories) in combination with expression vectors coding for either wild-type or mutant (G85R or G93A) c-Myc-tagged hSOD1s (1 $\mu \mathrm{g})$. Transfection was performed with FuGENE6 Transfection Reagent (Roche). Immunocytochemical stainings using a monoclonal anti-Human c-Myc antibody (1:200, BD Biosciences Pharmingen) revealed that EGFP and c-Myc-tagged proteins colocalize in $95 \%$ of cases.

hSOD1 expression levels were determined on transfected astrocytes immunostained for c-Myc by immunofluorescence quantification as follows. Average fluorescence intensity from transfected astrocytes was measured and expressed as fluorescence intensity arbitrary units on a linear scale of 0-256 in nonsaturating condition of the camera, using the ImageJ software. Fluorescence intensity values were then expressed relative to mean fluorescence intensity obtained from the nontransfected cells (background noise).

No significant difference in the expression levels was detected between the wild-type and the mutant proteins ( $\mathrm{hSOD} 1^{\mathrm{WT}}$ expression level was set as 100\%; hSOD1 ${ }^{\text {G93A. }} 123 \pm 13.1 \%$ versus hSOD $^{\text {WT. }}{ }^{\text {; }}$ hSOD1 ${ }^{\text {G85R. }} 116.4 \pm 11.8 \%$ versus $\mathrm{hSOD1}{ }^{\mathrm{WT}} ; n=50$ cells/genotype; values represent the mean \pm S.E.M. of three independent experiments; $P=0.46$, one-way ANOVA). Pharmacological experiments were carried out $48 \mathrm{~h}$ after transfection.

Expression of the glutamate transporters EAAT1/GLAST and EAAT2/GLT1 was evaluated on astrocyte cultures fixed with $4 \%$ buffered paraformaldehyde. EAAT1/GLAST and EAAT2/GLT1 were detected using rabbit polyclonal antibodies ( 0.5 and $1 \mu \mathrm{g} / \mathrm{ml}$, respectively). GFAP was detected with a mouse monoclonal antibody (clone G-A-5, 1:200, Chemicon).

Pharmacological treatments in vitro. Astrocyte cultures were exposed to one or combinations of the following agents for $30 \mathrm{~min}$ : L-Glutamate $(500 \mu \mathrm{M})$, CNQX $(10 \mu \mathrm{M})$, MCPG $(500 \mu \mathrm{M})$ MPEP $(200 \mathrm{nM})$, GYKI $52466(50 \mu \mathrm{M})$, DHPG $(100 \mu \mathrm{M})$, TBOA $(200 \mu \mathrm{M})$. All agents were from Tocris Bioscience, except L-Glutamate, from Sigma. After removal of the agents, astrocytes were allowed to recover at $37^{\circ} \mathrm{C}$ for $24 \mathrm{~h}$.

Astrocyte toxicity assays. The toxic effect of pharmacological treatments to astrocytes in culture was determined by double staining with the fluorescent nuclear dye Hoechst 33342 (Sigma) and anti-active caspase-3 immunocytochemistry using a rabbit polyclonal antibody (Cell Signalling). The number of astrocytes showing condensed nuclei and active caspase- $324 \mathrm{~h}$ after the pharmacological challenge was counted in a blind manner by two independent operators. For mouse cultures, the number of dying astrocytes was counted in 8-10 microscopic fields $(40 \times)$ per coverslip and expressed as percentage of the total number of cells present in the field. For transfected rat astrocytes, it was expressed as percentage of the total number of transfected cells (EGFP-positive) present in the coverslip. In each experiment, 2-3 coverslips/condition were counted and experiments were replicated as indicated in the legends.

Extracellular glutamate concentration in the astrocyte cultures. Endogenous glutamate accumulated in the supernatant of astrocytes incubated with TBOA $200 \mu \mathrm{M}$ for $30 \mathrm{~min}$ was measured by a specific enzymatic assay, as described previously. ${ }^{40}$ Briefly, cell supernatant was introduced in a $1 \times 1 \mathrm{~cm}$ cuvette (Hellma Italia) inside a LS55 computerized spectrofluorometer (Perkin-Elmer) at $37^{\circ} \mathrm{C}$ under continuous stirring in a buffer containing (in $\mathrm{mM}$ ): $\mathrm{NaCl} 120, \mathrm{KCl} 3.1, \mathrm{NaH}_{2} \mathrm{PO}_{4} 1.25$, HEPES-Na 25, $\mathrm{MgCl}_{2} 1$, glucose 4, $\mathrm{CaCl}_{2} 2$ at $\mathrm{pH} 7.4$, added with glutamate dehydrogenase $(\mathrm{GDH}, 15.5 \mathrm{U} / \mathrm{ml})$ and $1 \mathrm{mM} \mathrm{NADP}^{+}$. Glutamate present in the cell medium was oxidized by GDH to $\alpha$-ketoglutarate with the formation of NADPH and fluorescence emission at $430 \mathrm{~nm}$ (excitation light $335 \mathrm{~nm}$ ). Glutamate was quantified referring to the standard curves constructed with exogenous glutamate.

Pharmacological treatments in vivo. $\mathrm{hSOD} 1^{\mathrm{G} 93 \mathrm{~A}}$ mice were administered daily $30 \mathrm{mg} / \mathrm{kg}$ MPEP or saline intraperitoneally starting at the age of 40 days ( $n=18$ mice for each condition). Mice were thereafter kept under daily observation and weighted once a week. Since decline in peak body weight is considered the earliest observable measure of disease onset and strictly correlates with decline in motor performance, ${ }^{7,8}$ the onset of clinical disease was defined by the achievement of peak body weight. End stage was defined as the time at which animals were unable to right themselves within $30 \mathrm{~s}$ when placed on their side.

Acknowledgements. We are grateful to P Caroni, P Clarke and J Meldolesi for scientific discussions and advice; NC Danbolt for providing the anti-GLT1 and anti-GLAST antibodies; P Bezzi, S Vesce and V Schubert for critical reading and comments on the manuscript; GE Rovati e G Gambino for statistical advice; C Cafè and D Scirea for contributions in the early phases of this study; G Biondi, F Niccolini and $F$ Martorana for experimental help; G Simonutti for technical assistance with confocal microscopy. This work was supported by a grant from Fondazione Telethon (GGP05244) and an EMBO long-term fellowship (ALTF 279-2002) to DR and by grants from Fondazione Telethon (GGP02052), Fondazione Cariplo, Ministero Italiano della Università e Ricerca (COFIN, FIRB, FIRST) to AV.

1. Rosen DR, Siddique T, Patterson D, Figlewicz DA, Sapp P, Hentati A et al. Mutations in $\mathrm{Cu} / \mathrm{Zn}$ superoxide dismutase gene are associated with familial amyotrophic lateral sclerosis. Nature 1993; 362: 59-62.

2. Gurney ME, Pu H, Chiu AY, Dal Canto MC, Polchow CY, Alexander DD et al. Motor neuron degeneration in mice that express a human $\mathrm{Cu}, \mathrm{Zn}$ superoxide dismutase mutation. Science 1994; 264: 1772-1775. 
3. Bruijn LI, Becher MW, Lee MK, Anderson KL, Jenkins NA, Copeland NG et al. ALS-linked SOD1 mutant G85R mediates damage to astrocytes and promotes rapidly progressive disease with SOD1-containing inclusions. Neuron 1997; 18: 327-338.

4. Howland DS, Liu J, She Y, Goad B, Maragakis NJ, Kim B et al. Focal loss of the glutamate transporter EAAT2 in a transgenic rat model of SOD1 mutant-mediated amyotrophic latera sclerosis (ALS). Proc Natl Acad Sci USA 2002; 99: 1604-1609.

5. Jaarsma D, Teuling E, Haasdijk ED, De Zeeuw Cl, Hoogenraad CC. Neuron-specific expression of mutant superoxide dismutase is sufficient to induce amyotrophic lateral sclerosis in transgenic mice. J Neurosci 2008; 28: 2075-2088.

6. Clement AM, Nguyen MD, Roberts EA, Garcia ML, Boillee S, Rule M et al. Wild-type nonneuronal cells extend survival of SOD1 mutant motor neurons in ALS mice. Science 2003; 302: 113-117.

7. Boillee S, Yamanaka K, Lobsiger CS, Copeland NG, Jenkins NA, Kassiotis G et al. Onset and progression in inherited ALS determined by motor neurons and microglia. Science 2006; 312: 1389-1392.

8. Yamanaka K, Chun SJ, Boillee S, Fujimori-Tonou N, Yamashita H, Gutmann DH et al. Astrocytes as determinants of disease progression in inherited amyotrophic lateral sclerosis. Nat Neurosci 2008; 11: 251-253.

9. Beers DR, Henkel JS, Xiao Q, Zhao W, Wang J, Yen AA et al. Wild-type microglia extend survival in PU.1 knockout mice with familial amyotrophic lateral sclerosis. Proc Natl Acad Sci USA 2006; 103: 16021-16026.

10. Nagai M, Re DB, Nagata T, Chalazonitis A, Jessell TM, Wichterle $\mathrm{H}$ et al. Astrocytes expressing ALS-linked mutated SOD1 release factors selectively toxic to motor neurons. Nat Neurosci 2007; 10: 615-622.

11. Di Giorgio FP, Carrasco MA, Siao MC, Maniatis T, Eggan K. Non-cell autonomous effect of glia on motor neurons in an embryonic stem cell-based ALS model. Nat Neurosci 2007; 10 608-614.

12. Van Damme P, Bogaert E, Dewil M, Hersmus N, Kiraly D, Scheveneels W et al. Astrocytes regulate GluR2 expression in motor neurons and their vulnerability to excitotoxicity. Proc Natl Acad Sci USA 2007; 104: 14825-14830.

13. Rothstein JD, Van Kammen M, Levey Al, Martin LJ, Kuncl RW. Selective loss of glia glutamate transporter GLT-1 in amyotrophic lateral sclerosis. Ann Neurol 1995; 38: 73-84.

14. Guo H, Lai L, Butchbach ME, Stockinger MP, Shan X, Bishop GA et al. Increased expression of the glial glutamate transporter EAAT2 modulates excitotoxicity and delays the onset but not the outcome of ALS in mice. Hum Mol Genet 2003; 12: 2519-2532.

15. Rothstein JD, Patel S, Regan MR, Haenggeli C, Huang YH, Bergles DE et al. Beta-lactam antibiotics offer neuroprotection by increasing glutamate transporter expression. Nature 2005; 433: 73-77.

16. Pardo AC, Wong V, Benson LM, Dykes M, Tanaka K, Rothstein JD et al. Loss of the astrocyte glutamate transporter GLT1 modifies disease in SOD1(G93A) mice. Exp Neurol 2006; 201: 120-130

17. Pasinelli $\mathrm{P}$, Houseweart MK, Brown Jr RH, Cleveland DW. Caspase-1 and -3 are sequentially activated in motor neuron death in $\mathrm{Cu}, \mathrm{Zn}$ superoxide dismutase-mediated familial amyotrophic lateral sclerosis. Proc Natl Acad Sci USA 2000; 97: 13901-13906.

18. Chiu AY, Zhai P, Dal Canto MC, Peters TM, Kwon YW, Prattis SM et al. Age-dependent penetrance of disease in a transgenic mouse model of familial amyotrophic latera sclerosis. Mol Cell Neurosci 1995; 6: 349-362.

19. Mouser PE, Head E, Ha KH, Rohn TT. Caspase-mediated cleavage of glial fibrillary acidic protein within degenerating astrocytes of the Alzheimer's disease brain. Am J Pathol 2006 168: 936-946.

20. Alvarez FJ, Villalba RM, Zerda R, Schneider SP. Vesicular glutamate transporters in the spinal cord, with special reference to sensory primary afferent synapses. J Comp Neurol 2004; 472: 257-280

21. Choi DW, Maulucci-Gedde M, Kriegstein AR. Glutamate neurotoxicity in cortical cell culture. J Neurosci 1987; 7: 357-368.
22. Inglis FM, Furia F, Zuckerman KE, Strittmatter SM, Kalb RG. The role of nitric oxide and NMDA receptors in the development of motor neuron dendrites. J Neurosci 1998; 18 10493-10501.

23. Kabashi E, Agar JN, Taylor DM, Minotti S, Durham HD. Focal dysfunction of the proteasome: a pathogenic factor in a mouse model of amyotrophic lateral sclerosis. $J$ Neurochem 2004; 89: 1325-1335.

24. Araque A, Parpura V, Sanzgiri RP, Haydon PG. Tripartite synapses: glia, the unacknowledged partner. Trends Neurosci 1999; 22: 208-215.

25. Volterra A, Meldolesi J. Astrocytes, from brain glue to communication elements: the revolution continues. Nat Rev Neurosci 2005; 6: 626-640.

26. Pasti L, Volterra A, Pozzan T, Carmignoto G. Intracellular calcium oscillations in astrocytes: a highly plastic, bidirectional form of communication between neurons and astrocytes in situ. J Neurosci 1997; 17: 7817-7830.

27. Wang X, Lou N, Xu Q, Tian GF, Peng WG, Han X et al. Astrocytic Ca2+ signaling evoked by sensory stimulation in vivo. Nat Neurosci 2006; 9: 816-823.

28. Matsui K, Jahr CE. Exocytosis unbound. Curr Opin Neurobiol 2006; 16: 305-311.

29. Paukert M, Bergles DE. Synaptic communication between neurons and NG2+ cells. Curr Opin Neurobiol 2006; 16: 515-521.

30. Matthias K, Kirchhoff F, Seifert G, Huttmann K, Matyash M, Kettenmann $\mathrm{H}$ et al, Segregated expression of AMPA-type glutamate receptors and glutamate transporters defines distinct astrocyte populations in the mouse hippocampus. J Neurosci 2003; 23 1750-1758.

31. Williams TL, Day NC, Ince PG, Kamboj RK, Shaw PJ. Calcium-permeable alphaamino-3-hydroxy-5-methyl-4-isoxazole propionic acid receptors: a molecular determinant of selective vulnerability in amyotrophic lateral sclerosis. Ann Neurol 1997; 42: 200-207.

32. Van Damme P, Van Den Bosch L, Van Houtte E, Callewaert G, Robberecht W. GluR2dependent properties of AMPA receptors determine the selective vulnerability of motor neurons to excitotoxicity. J Neurophysiol 2002; 88: 1279-1287.

33. Kawahara $\mathrm{Y}$, Ito K, Sun H, Aizawa H, Kanazawa I, Kwak S. Glutamate receptors: RNA editing and death of motor neurons. Nature 2004; 427: 801.

34. Alexianu ME, Ho BK, Mohamed AH, La Bella V, Smith RG, Appel SH. The role of calciumbinding proteins in selective motoneuron vulnerability in amyotrophic lateral sclerosis. Ann Neurol 1994; 36: 846-858.

35. Anneser JM, Borasio GD, Berthele A, Zieglgansberger W, Tolle TR. Differential expression of group I metabotropic glutamate receptors in rat spinal cord somatic and autonomic motoneurons: possible implications for the pathogenesis of amyotrophic lateral sclerosis. Neurobiol Dis 1999; 6: 140-147.

36. Anneser JM, Chahli C, Borasio GD. Protective effect of metabotropic glutamate receptor inhibition on amyotrophic lateral sclerosis-cerebrospinal fluid toxicity in vitro. Neuroscience 2006; 141: 1879-1886.

37. Aronica E, Catania MV, Geurts J, Yankaya B, Troost D. Immunohistochemical localization of group I and II metabotropic glutamate receptors in control and amyotrophic lateral sclerosis human spinal cord: upregulation in reactive astrocytes. Neuroscience 2001; 105 509-520.

38. Vermeiren C, Hemptinne I, Vanhoutte N, Tilleux S, Maloteaux JM, Hermans E. Loss of metabotropic glutamate receptor-mediated regulation of glutamate transport in chemically activated astrocytes in a rat model of amyotrophic lateral sclerosis. J Neurochem 2006; 96 : 719-731.

39. Pun S, Santos AF, Saxena S, Xu L, Caroni P. Selective vulnerability and pruning of phasic motoneuron axons in motoneuron disease alleviated by CNTF. Nat Neurosci 2006; 9: 408-419.

40. Bezzi P, Domercq M, Brambilla L, Galli R, Schols D, De Clercq E et al. CXCR4-activated astrocyte glutamate release via TNFalpha: amplification by microglia triggers neurotoxicity Nat Neurosci 2001; 4: 702-710.

\section{Supplementary Information accompanies the paper on Cell Death and Differentiation website (http://www.nature.com/cdd)}

